\title{
THE GLUCOSE MOBILIZATION RATE IN HYPERTHYROIDISM *
}

\author{
BERTRAM J. SANGER, M.D., $\Lambda$ ND ELSIE G. HUN \\ SEW YORK
}

In a preliminary paper ${ }^{1}$ on this subject the results of some observations on the glucose mobilization rate in hyperthyroidism were reported. In this paper the results will be exhibited in greater detail. Ten normal controls and ten well marked cases of exophthalmic goiter have been studied under identical conditions. All the cases of hyperthyroidism were of the same type, i. e., exophthalmic goiter, with all the clinical manifestations of a well marked thyrotoxicosis.

The object of the experiments was to obtain some insight into the mechanism of so-called decreased carbohydrate tolerance in cases of hyperthyroidism. Through studies of the change in the blood sugar, the respiratory quotient and the total metabolism, before and after glucose ingestion, we derived our data for computing the carbohydrate utilization.

The procedure need not be gone over again in detail as it was clearly outlined in the preliminary paper. A Tissot spirometer, equipped with a Siebe-Gorman half face mask and Douglas valves, and a Haldane gas analysis apparatus, were used routinely in all the experiments under the standard technic for this type of work. Samples of the total expired air were taken over mercury in a special s.3mpling tube for analysis. All technical results and calculations were carefully checked over, and all sources of error eliminated, in so far as it was possible. Altogether the experiment occupied about three and one-ialf hours. The fasting patient was put to rest for from one-half to three-y:tarters of an hour after which a basal period was run. The mask was then replaced for a second basal period. The basal respiratory quotient and total metabolism used in our calculations were the average of these two periods. As soon as these were completed, blood was taken for a fasting blood sugar, and the glucose was given in a mixture of grapefruit juice-for the most part the dosage was $1.75 \mathrm{gm}$. per kilogram body weight. ${ }^{2}$ In one or two of the first experiments $100 \mathrm{gm}$. was given without regard to weight. Fifteen minutes after the ingestion of the glucose, the blood sugar was taken, and five minutes later (i. e., twenty minutes after glucose ingestion), the mask was replaced for

* From the Department of Medicine. College of Physicians and Surgeons. Columbia University, and the Presbyterian Hospital.

1. Sanger, B. I.: Proc. Soc. Exper. Biol. \& M. 17:117, 1921.

2. Janney and Isaacson: J. A. M. A. 70:1131 (April 20) 1918. 
the first postglucose period. The duration of the periods was usually ten minutes. This made the first period end on the half hour after the taking of the glucose. From then on until the end of the experiment a period was run every half hour, making in all five postglucose periods. Blood was withdrawn again one hour and two hours after the glucose ingestion. This gave us two basal periods and five postglucose periods, and four samples of blood for analysis. A specimen of urine taken at the end of the experiment was tested for glucose. With the data obtained, the calculations were made and tabulated.

The comparison of the change in the metabolic rate between the normals and the cases of hyperthyroidism was very confusing. The percentage rise above basal was much less in the cases of exophthalmic goiter than in the controls, but if the abnormal cases were figured on the basis of what the rise in calories would have amounted to had the patient's basal metabolism been normal, then the results were very

Table 1.-Blood Sugar Curves in Normal Control.s

\begin{tabular}{|c|c|c|c|c|c|c|c|c|c|c|c|}
\hline \multirow[b]{3}{*}{ Fasting.. } & \multicolumn{10}{|c|}{ Name } & \multirow{3}{*}{$\begin{array}{c}\text { Aver- } \\
\text { age } \\
0.85\end{array}$} \\
\hline & C.L. & H.D. & W.V.G. & F.H. & B.S. & M.C. & M.C. & H.J. & R.Mc. & H.R.G. & \\
\hline & 0.89 & 0.83 & $0.9 \vec{i}$ & 0.92 & 0.80 & 0.87 & 0.72 & 1.10 & 0.92 & Lost & \\
\hline 15 minutes........ & 0.98 & 1.05 & 1.19 & 1.37 & 1.09 & 1.10 & 1.24 & 1.20 & 1.03 & 0.76 & \\
\hline fo minutes........ & 1.30 & 1.08 & 0.98 & 1.51 & 1.35 & 1.26 & 1.54 & 1.67 & 1.40 & 0.78 & \\
\hline 120 minutes. ...... & 0.95 & 0.95 & 1.10 & 1.14 & 1.15 & 1.17 & 1.20 & 1.20 & 1.03 & 0.73 & \\
\hline Range............ & 0.41 & 0.25 & 0.28 & 0.59 & 0.55 & 0.39 & 0.82 & 0.57 & 0.48 & $\ldots$ & 0.48 \\
\hline
\end{tabular}

TABle 2.-Blood Sugar Curves in Cases of Hyperthyroidism

\begin{tabular}{|c|c|c|c|c|c|c|c|c|c|c|c|}
\hline \multirow{7}{*}{ 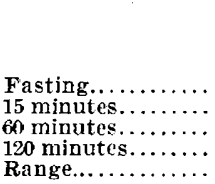 } & \multirow{7}{*}{$\begin{array}{l}\text { F.B. } \\
0.91 \\
1.3 \\
2.10 \\
1.85 \\
0.94\end{array}$} & \multirow{7}{*}{$\begin{array}{c}\text { H.G. } \\
0.95 \\
1.25 \\
2.30 \\
2.30 \\
1.35\end{array}$} & \multicolumn{2}{|c|}{ 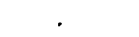 } & \multicolumn{2}{|c|}{ Name } & \multirow[b]{2}{*}{ M.D. } & \multirow[b]{2}{*}{ G.S. } & \multirow[b]{2}{*}{ B.S. } & \multirow[b]{2}{*}{ F.R. } & \multirow{3}{*}{$\begin{array}{l}\text { Aver- } \\
\text { age } \\
0.99\end{array}$} \\
\hline & & & F.K. & C.E. & L.M. & A.S. & & & & & \\
\hline & & & 1.02 & 1.03 & 0.93 & 1.13 & 0.91 & 1.00 & 1.12 & 0.94 & \\
\hline & & & 1.54 & 1.40 & 1.37 & 2.00 & 1.50 & 1.40 & 1.74 & 1.30 & \\
\hline & & & 2.32 & 2.04 & 1.80 & 2.32 & 1.90 & 1.80 & 2.10 & 1.50 & \\
\hline & & & 2.00 & 1.50 & 1.30 & 1.07 & 1.66 & 1.04 & 1.40 & 1.07 & \\
\hline & & & 1.30 & 1.01 & 0.87 & 1.19 & 0.99 & 0.80 & 0.98 & 0.56 & 1.000 \\
\hline
\end{tabular}

similar to those obtained in the normal controls. It seems likely, therefore, that the specific dynamic action of carbohydrates is much the same in cases of hyperthyroidism and in normal persons.

Taking as a normal blood sugar curve, one that has a fasting level from 0.7 to $1.1 \mathrm{gm}$. per liter, that reaches its peak in one hour after glucose ingestion, rarely going higher than 1.7 , and which tends to reach its fasting level within two hours, then our ten normal controls were well within this range (Table 1 ).

In no case did glucose appear in the urine.

The cases of hyperthyroidism showed essentially normal fasting blood sugars, though on the average they were somewhat higher than the fasting values found in the normals (Table 2). The range in the great majority of cases studied, however, was quite different. There 
was a distinct rise after fifteen minutes, but the peak was not reached until after one hour when it was distinctly above the normal range. The blood sugar, in the great majority of cases, remained distinctly elevated after two hours. There was one notable exception to this in one case (E. R., a very distinct case of exophthaimic goiter), in which the blood sugar curve was entirely normal. At the time of the test this patient had auricular fibrillation which was almost certainly secondary to the thyrotoxicosis, as it cleared up entirely (electrocardiograph evidence) under treatment. This rather strikingly normal curve in a well marked case, along with one or two other cases in the series that were within normal variation, showed that all cases of hyperthyroidism do not have deranged carbohydrate metabolism if judged by blood sugar curves alone. Five of the cases showed glycosiria after the glucose ingestion, three were sugar free and two were not tested through error.

TABle 3.-Curves of Respiratory Qrotient in Normal Controls

\begin{tabular}{|c|c|c|c|c|c|c|c|c|c|c|c|}
\hline \multirow{4}{*}{ 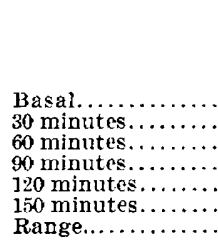 } & \multicolumn{10}{|c|}{ Name } & \multirow{2}{*}{$\begin{array}{l}\text { Aver- } \\
\text { age }\end{array}$} \\
\hline & C.L. & H.D. & W.V.G. & E.H. & B.S. & M.C. & M.C. & H.J. & R.Me. & H.R.G. & \\
\hline & $\begin{array}{l}0.78 \\
0.82 \\
0.80 \\
0.89 \\
0.87 \\
0.94\end{array}$ & $\begin{array}{l}0.83 \\
0.81 \\
0.80 \\
0.88 \\
0.88 \\
0.90\end{array}$ & $\begin{array}{l}0.75 \\
0.84 \\
0.88 \\
0.88 \\
0.84 \\
0.90\end{array}$ & $\begin{array}{l}0.77 \\
0.80 \\
0.80 \\
0.90 \\
0.92 \\
0.90\end{array}$ & $\begin{array}{l}0.78 \\
0.80 \\
0.84 \\
0.86 \\
0.88 \\
0.86\end{array}$ & $\begin{array}{l}0.79 \\
0.82 \\
0.88 \\
0.89 \\
0.92 \\
0.93\end{array}$ & $\begin{array}{l}0.83 \\
0.83 \\
0.86 \\
0.83 \\
0.92 \\
0.90\end{array}$ & $\begin{array}{l}0.85 \\
0.83 \\
0.84 \\
0.88 \\
0.93 \\
0.89\end{array}$ & $\begin{array}{l}0.83 \\
0.88 \\
0.84 \\
0.88 \\
0.93 \\
0.92\end{array}$ & $\begin{array}{l}0.75 \\
0.79 \\
0.81 \\
0.88 \\
0.83 \\
0.87\end{array}$ & \\
\hline & 0.16 & 0.09 & 0.15 & 0.15 & 0.10 & 0.14 & 0.09 & 0.10 & 0.10 & 0.12 & 0.12 \\
\hline
\end{tabular}

TABLE 4.-Curves of Respiratory Quotient in Casis of Hyperthyroidism

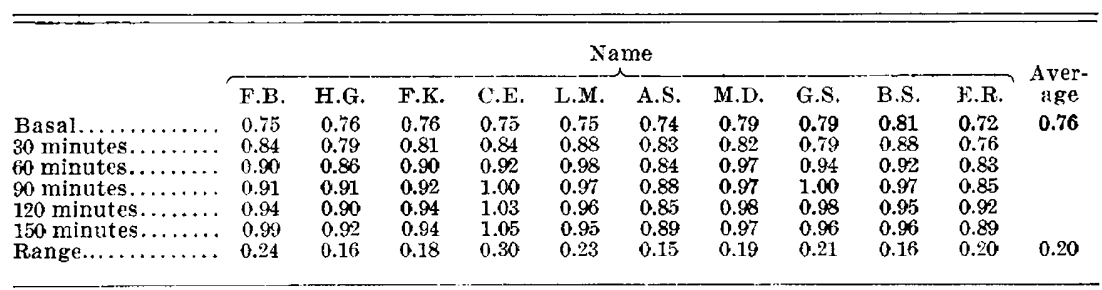

The respiratory quotients when studied in phases offered the most interesting data in our experiments. The basal quotient on the average in the cases of hyperthyroidism was slightly lower than in the normal controls- 0.76 as compared to 0.80 (Tables 3 and 4 ). In the cases of exophthalmic goiter after the dose of glucose had been given, the quotients rose rapidly to a high figure, in one case going as high as 1.05 , whereas in the normal cases, the quotients rose more slowly, and did not reach nearly so high a point. The high level of the respiratory quotient was maintained for a longer time in the cases of hyperthyroidism than in the normal controls, and at the end of the two and one-half hours was still very high. The average range from the basal to the peak in the cases of hyperthyroidism was twenty points, 
while that in the normals was only twelve, the greatest being thirty in the one and sixteen in the other. This proves very strikingly that individuals with thyrotoxicosis can burn carbohydrate readily, in fact, do burn it with avidity, and along with the fact that their blood sugar stays high suggests very probably that there is an inability for storing carbohydrate in these cases. For if they burn it more rapidly than do normals, and in spite of this maintain a high blood sugar, then obviously they cannot be storing it. There is good experimental evidence to substantiate this view. ${ }^{3}$

From the figures of the respiratory quotient we derived our calculations for the utilization of carbohydrate. Fifteen per cent. was deducted from the total calories per hour for that portion of the heat derived from protein metabolism. ${ }^{4}$ The remaining calories were assumed as coming from carbohydrate and fat, and were apportioned to each of these metabolites according to the percentage tables of Zunst and Schumburg as modified by Riche and Lusk. The respiratory quotients were used directly without deductions for protein metabolism as derived from the urinary nitrogen, that is, they were not nonprotein respiratory quotients. For practical purposes of comparison this seemed adequate, though we realized that nitrogen studies would have made our data somewhat more accurate. The difficulty of collecting specimens over short periods, however, and the uncertainty of the nitrogen in the urine collected representing the protein utilized cluring the period of the experiment, due to the nitrogen lag, decided us to leave urinary studies out of our work. Tables 5 and 6 show the calculations in each case.

It is evident that in the normal cases following the dose of glucose, there was an increase in the number of grams of carbohydrate utilized over the amount utilized at basal. This increase, however, was only a small proportion of the quantity ingested, the total for the two. and one-half hours following the ingestion of the close being on the average 18.1 per cent. of the amount taken (Table 7). This, plus the rapid rise and fall in the blood sugar, makes us feel that in these cases the greater part of the carbohydrate is stored.

In the cases of hyperthyroidism, on the other hand, an average of 36.1 per cent. (Table 8) of the amount ingested was burned over the same period (two and one-half hours) and at the end of this period the blood sugar was still greatly elevated. The amount of carbohydrate accounted for by this increased blood sugar is very small, only amounting to a few grams, but when we realize that the maintained high concentration of sugar in the blood means a high concentration of sugar in the tissues, this figure is more significant.

3. Cramer and Krause: Proc. Roy. Soc., Ser. B. 86:50, 1913. Kuriyama: J. Biol. Chem. 33: 193, 1918.

4. Voit, E.: Ztschr. f. Biol. 41:188, 1901. 
Table 5.-Data on Ten Normal Controls After Glucose Ingestion

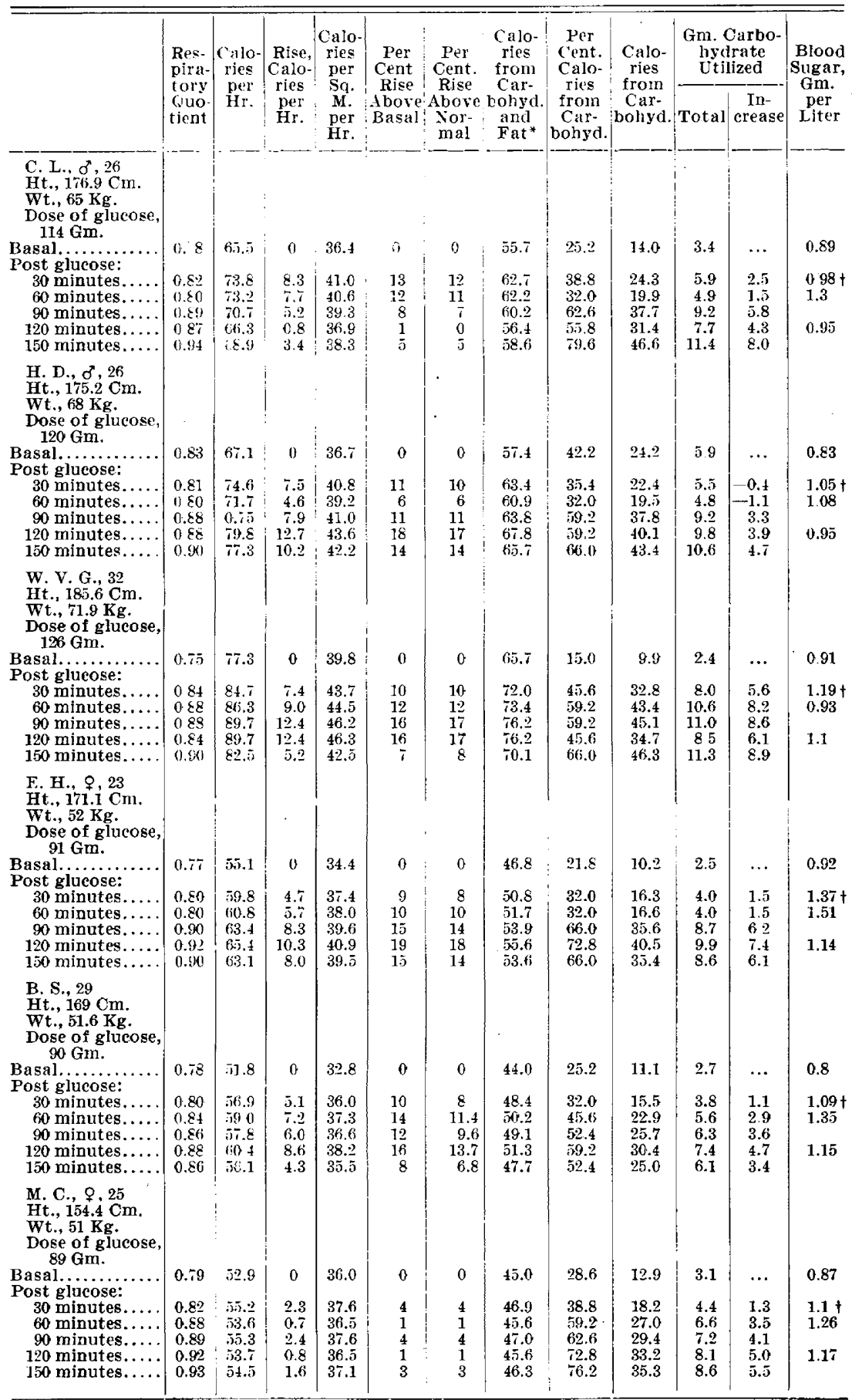

* 15 per cent. deducted from calories per hour for calories from (nitrogen) protein.

+ Blood sugar 15 minutes post glucose. 
Table 5.-Data on Ten Normal Controls

After Glucose Ingestion-(Continued)

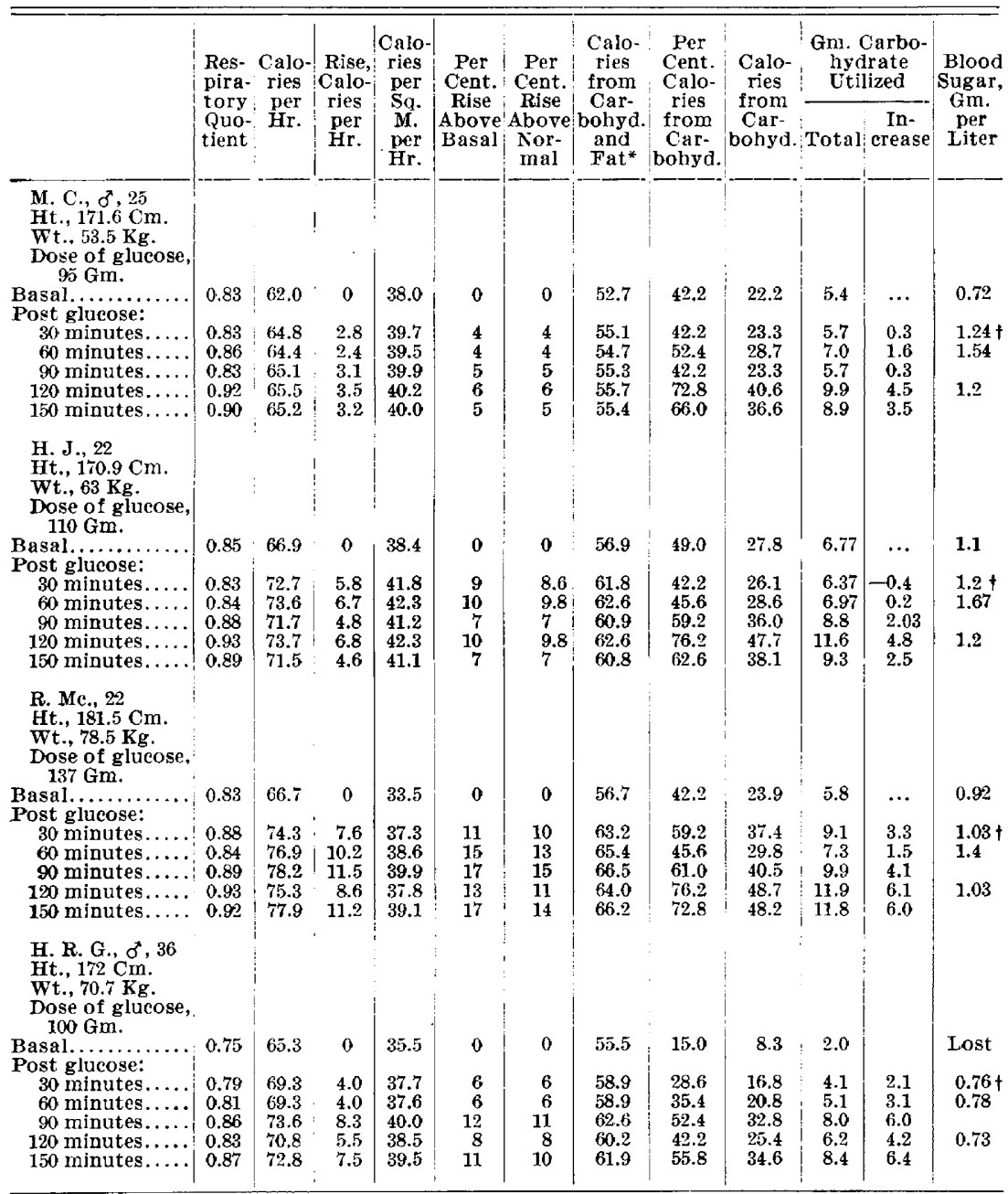

* 15 per cent. deducted from calories per hour for calories from (nitrogen) protein.

$\dagger$ Blood sugar 15 minutes post glucose.

The explanation seems obvious. In cases of hyperthyroidism there is a deficiency in the ability to store carbohydrate. This makes for a carbohydrate plethora and the carbohydrate plethora stimulates carbohydrate metabolism. This inability to store carbohydrate appears to be the only logical explanation of the carbohydrate plethora, as it cannot be due to the inability of the tissues to utilize it in this condition. Besides, this explanation fits in with the experimental evidence, as Cramer and his collaborators and Kuriyama have shown that thyroid 
Table 6.-Data on Ten Cases of Hyperthyrotdism in Which Glucose Was Administered

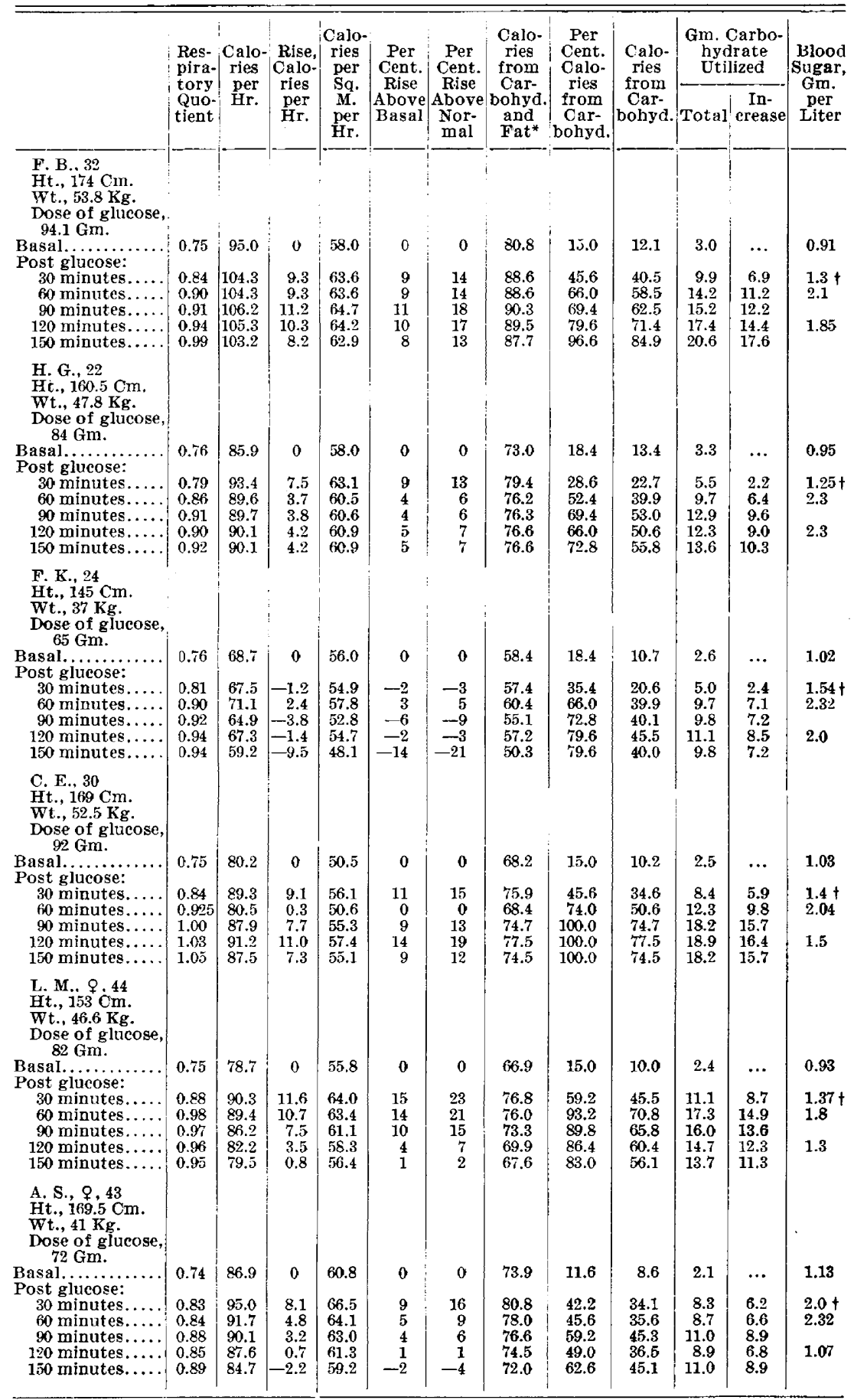

* 15 per cent. deducted from calories per hour for calories from (nitrogen) protein.

$\dagger$ Blood sugar 15 minutes post glucose. 
TABle 6.-Data on Ten Cases of Hyperthyroidism in Which Glucose Was Administered-(Continued)

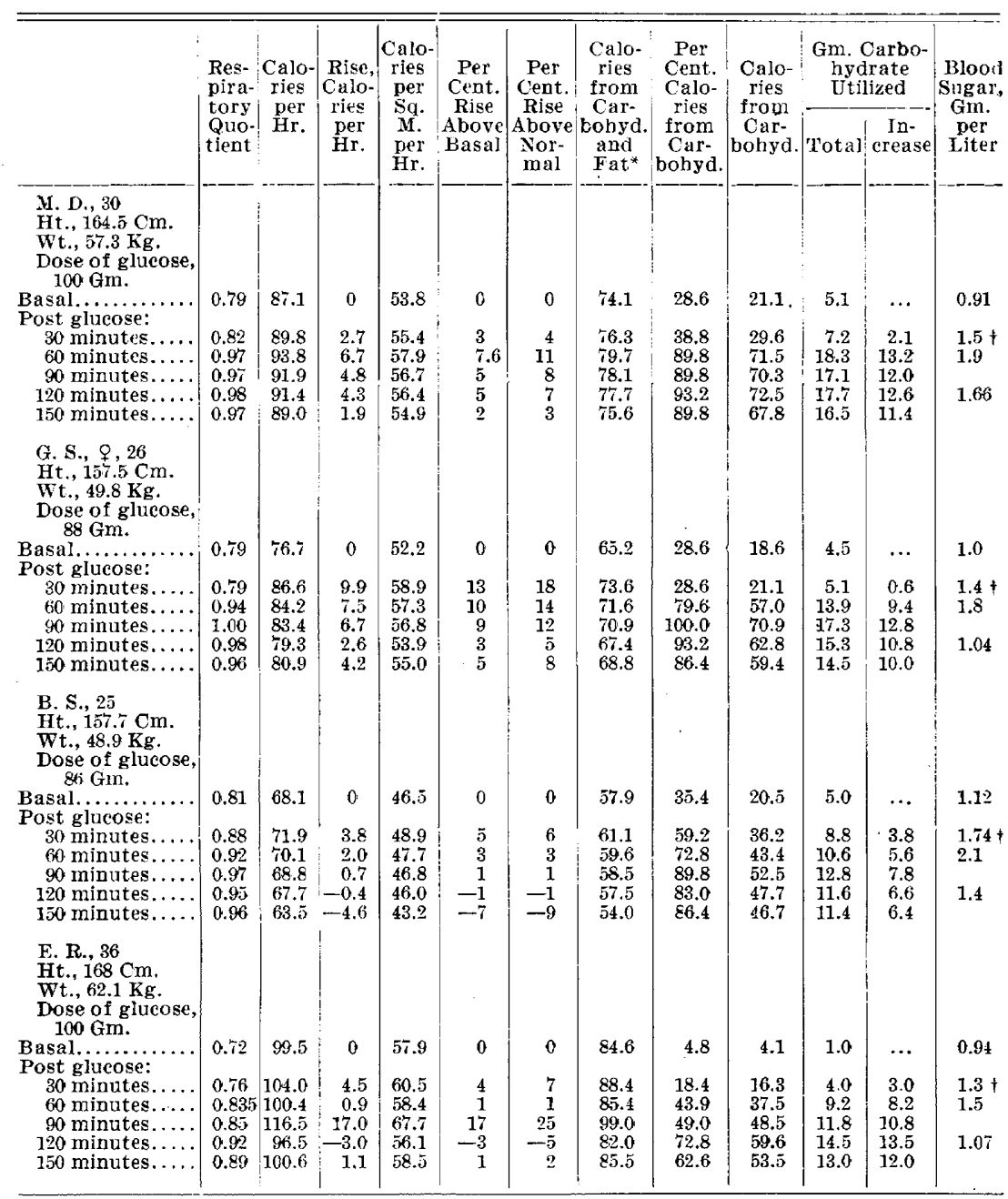

* 15 per cent. deducted from calories per hour for calories from (nitrogen) protein.

$\dagger$ Blood sugar 15 minutes post glucose.

Table 7.-Grams of Carbohydrate Utulized by Normal Controls

\begin{tabular}{|c|c|c|c|c|c|c|c|c|c|c|c|}
\hline \multirow{5}{*}{$\begin{array}{r}\text { Total gm. carbo- } \\
\text { hydrate utilized } \\
\text { in } 21 / 2 \text { hours...... } \\
\text { Dose of glucose, } \\
\text { gm............... } \\
\text { Percentage of dose } \\
\text { utilized............. }\end{array}$} & \multicolumn{10}{|c|}{ Name } & \multirow{2}{*}{$\begin{array}{l}\text { Aver- } \\
\text { age }\end{array}$} \\
\hline & C.L. & H.D. & W.V.G. & F.H. & B.S. & M.C. & M.C. & H.J. & R.Mc. & H.R.G. & \\
\hline & 19.5 & 19.9 & 24.6 & 17.6 & 14.6 & 17.4 & 18.5 & 21.4 & 25.0 & 15.9 & 19.4 \\
\hline & 114 & 120 & 126 & 91 & 90 & 89 & 95 & 110 & 137 & 100 & \\
\hline & 17.1 & 16.6 & $19 . \overline{5}$ & 19.3 & 16.2 & 19.6 & 19.5 & 19.5 & 18.3 & 15.9 & 18.1 \\
\hline
\end{tabular}


fed rats on high carbohydrate diets had negligible amounts of glycogen stored in their livers, while control animals on the same diet showed large amounts. There is also some clinical eridence that points to the lack of glycogen reserve in hyperthyroidism. It has been observed that subjects with exophthalmic goiter can be sent into acidosis very easily by brief periods of fasting. A very striking example of this was seen. $^{5}$ The patient entered the hospital for the treatment of hyperthyroidism. As she had a glycosuria on general diet she was put on the "standard strict diet" (approximately $10 \mathrm{gm}$. carbohydrate; $100 \mathrm{gm}$. protein; $100 \mathrm{gm}$. fat) in an attempt to clear up the glycosuria. She gradually went into acidosis. This was soon cleared up under carbohydrate feeding. The carbohydrate in the diet was then rapidly increased until $190 \mathrm{gm}$. were given per day without appreciable quantitative change in the glycosuria. A subsequent diet with restricted carbohydrate promptly brought on an acidosis with impending coma, which was quickly cleared up by carbohydrate feeding. This suggests that the patient had a very small glycogen reserve.

TABle 8.-Grams of Carbohydrate Utilized by Subjects With HYPERTH YROIDISM

\begin{tabular}{|c|c|c|c|c|c|c|c|c|c|c|c|}
\hline \multirow{3}{*}{$\begin{array}{l}\text { Total gm. carbo. } \\
\text { hydrate utilized } \\
\text { in } 21 / 2 \text { hours..... }\end{array}$} & \multicolumn{10}{|c|}{ Name } & \multirow{2}{*}{$\begin{array}{l}\text { Aver- } \\
\text { age }\end{array}$} \\
\hline & F.B. & H.G. & F.K. & C.F. & L.M. & A.S. & M.D. & G.S. & B.S. & E.R. & \\
\hline & 38.6 & 27.0 & 22.7 & 38.0 & 36.3 & 23.9 & 38.3 & 33.0 & 27.6 & 26.2 & 31.2 \\
\hline $\begin{array}{r}\text { Dose of glucose, } \\
\text { gm..................... }\end{array}$ & 94 & 84 & 65 & $y_{2}$ & 82 & 72 & 100 & 88 & 86 & 100 & \\
\hline $\begin{array}{l}\text { Percent age of dose } \\
\text { utilizen........... }\end{array}$ & 41.1 & 32.2 & 34.9 & 41.3 & 44.3 & 33.2 & 38.3 & 37.5 & 32.1 & 26.2 & 36.1 \\
\hline
\end{tabular}

\section{SLM MAR I}

Ten normal persons and ten subjects with exophthalmic goiter have been studied under identical conditions. The blood sugar curves in the control cases were entirely normal, while those in the cases of hyperthyroidism, for the most part, showed the usual variation, i. e., an abnormally high peak maintained over a prolonged period. The respiratory quotients in the normal cases revealed normal carbohydrate storage and response while those in the cases of hyperthyroidism showed a greater and more rapid rise, which made for a striking increase in the carbohydrate utilization.

\section{CONCLUSIONS}

1. The abnormal blood sugar curves reported heretofore in cases of hyperthyroidism were found, for the most part, in our cases. Normal curves in strikingly toxic cases, however, were not unusual.

5. Preshyterian Hospital Surgical Service, History 30699. 
2. It has been shown that in hyperthyroidism, sugar, when it is offered to the tissues as a fuel, is burned with great avidity. The increased utilization of carbohydrate after carbohydrate ingestion, along with the maintained high blood sugar, points toward an inability to store glucose-most probably a failure of liver storage, due to some toxic change in the liver caused by the disease. This fits in with the results found in thyroid fed animals, and is suggested by clinical cases of exophthalmic goiter in which carbohydrate restriction is attempted. 